\title{
Assessment of a home-made pain/discomfort questionnaire in patients undergoing coronary angiography: a feasibility study
}

\author{
Matea Hudolin', \\ Zdenka Čurić \\ Marko Ćurković ${ }^{3}$, \\ Tomislav Letilović2* \\ University of Zagreb School \\ of Medicine, Zagreb, Croatia \\ ${ }^{2}$ Clinical Hospital Merkur, \\ Zagreb, Croatia \\ ${ }^{3}$ Psychiatry Clinic Vrapče, \\ Zagreb, Croatia
}

KEYWORDS: pain, discomfort, coronary angiography.

CITATION: Cardiol Croat. 2015;10(9-10):235. | Dol: http://dx.doi.org/10.15836/ccar.2015.235

*ADDRESS FOR CORRESPONDENCE: Tomislav Letilović, Clinical Hospital Merkur, Zajčeva 19, HR-10000 Zagreb, Croatia. Phone: +385-1-2461-390 / E-mail: letilovic@yahoo.com

ORCID: Matea Hudolin, http://orcid.org/0000-0003-4940-1860 • Zdenka Čurić, http://orcid.org/0000-0002-1141-6509 Marko Ćurković, http://orcid.org/0000-0002-4855-2133 • Tomislav Letilović, http://orcid.org/0000-0003-1229-7983

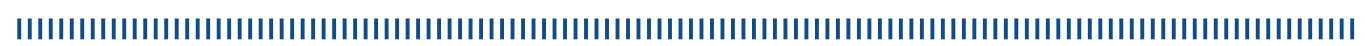

Coronary angiography is a medical procedure associated with a certain amount of pain and discomfort. ${ }^{1}$ We designed our own pain/discomfort questionnaire and conducted this initial study in order to assess its feasibility. Questionnaire consists of three types of questions. Firstly there are the ones addressing the pain and comfort issue in a semi-quantitative manner i.e. scoring of a sensation from 1 to 5 ( 1 being the lowest intensity of a sensation). Second types of questions are categorical ones and are also related to pain and discomfort. Lastly, there are informative questions mostly covering demographical data.

In a period of one month we collected data from 56 patients ( 36 male) undergoing elective diagnostic coronary angiography. Mean age of our patients was 63.3 \pm 9.4 years. Mean score for pain during the procedure was $2.1 \pm 0.67$ and for discomfort it was $2.16 \pm 0.92$. The pain after the procedure was scored with $1.71 \pm 0.80$ and the overall disability from the procedure with $1.78 \pm 0.80$. Pain during the procedure was graded significantly higher $(\mathrm{p}=0.036)$ in women than in men $(2.46 \pm 0.64$ vs. $2.0 \pm 0.65)$. Pain after the procedure was also graded higher $(p=0.047)$ in women $(2.07 \pm 0.88 \mathrm{vs}$. $1.51 \pm 0.66)$. There were no differences in the grading of the discomfort or the notion of the disability between the sexes. 55 patients (98\%) stated that they would undergo the same procedure again. All (56/56) of the patients declared that they would recommend the procedure either to other persons or their family members.

Initial results show that our questionnaire is feasible. Furthermore gathered data show some significant differences in pain sensation, induced by diagnostic coronary angiography, between women and men. We plan to strengthen our findings by including larger number of patients. In the future, using the same questionnaire, we plan to compare pain/comfort sensations in different invasive procedures conducted in our catheterization laboratories.

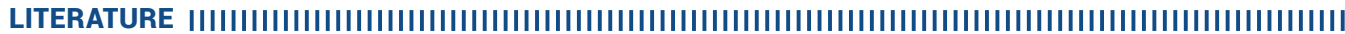

1. Pooler-Lunse C, Barkmann A, Fenwick B. Effects of modified positioning and mobilization on back pain and delayed bleeding in patients who had received heparin and undergone angiography. Heart Lung. 1996;25:117-123. PubMed: http://www.ncbi.nlm.nih.gov/pubmed/8682682
RECEIVED:

July 17, 2015

ACCEPTED:

September 17, 2015

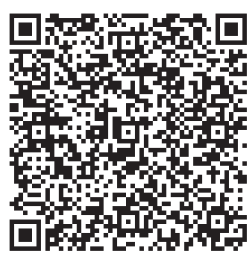

